\title{
Inhibition of poly(adenosine diphosphate-ribose) polymerase by the active form of vitamin $D$
}

\author{
JON G. MABLEY ${ }^{1}$, REBECCA WALLACE ${ }^{2}$, PÁL PACHER ${ }^{3}$, \\ KANNEGANTI MURPHY ${ }^{2}$ and CSABA SZABÓ S,4 $^{2,4}$ \\ ${ }^{1}$ School of Pharmacy and Biomolecular Sciences, University of Brighton, Brighton, UK; ${ }^{2}$ Inotek Pharmaceuticals \\ Corporation, Beverly, MA; ${ }^{3}$ National Institute of Health, NIAAA, Laboratory of Physiologic Studies, \\ Rockville, MD; ${ }^{4}$ Department of Surgery, UMDNJ-New Jersey Medical School, Newark, NJ, USA
}

Received January 9, 2007; Accepted February 21, 2007

\begin{abstract}
Vitamin D is well characterized for its role in mineral homeostasis and maintenance of normal skeletal architecture. Vitamin D has been demonstrated to exert antiinflammatory effects in a variety of disease states including diabetes, arthritis and inflammatory bowel disease. In these diseases poly[adenosine diphosphate (ADP)-ribose] polymerase (PARP) inhibitors have also proved effective as anti-inflammatory agents. Here we present data demonstrating that the active metabolite of vitamin $\mathrm{D}, 1 \alpha, 25$-dihydroxyvitamin D3, is a PARP inhibitor. UV irradiation-mediated PARP activation in human keratinocytes can be inhibited by treatment with vitamin $\mathrm{D}, 7$-dehydrocholesterol or $1 \alpha, 25$ dihydroxyvitamin D3. Inhibition of cytochrome P450 reversed the PARP inhibitory action of vitamin D and 7dehydrocholesterol, indicating that conversion to $1 \alpha, 25-$ dihydroxyvitamin D3 mediates their PARP inhibitory action. Vitamin D may protect keratinocytes against over-activation of PARP resulting from exposure to sunlight. PARP inhibition may contribute to the pharmacological and anti-inflammatory effects of vitamin D.
\end{abstract}

\section{Introduction}

Poly(ADP-ribose) polymerase-1 (PARP-1) is an abundant nuclear enzyme present in eukaryotes (1), which has been implicated in the cellular response to DNA injury. PARP-1 functions as a DNA damage sensor and as a signaling molecule binding to both single- and double-stranded DNA breaks. Upon binding to damaged DNA, PARP-1 forms

Correspondence to: Dr Jon G. Mabley, School of Pharmacy and Biomolecular Sciences, University of Brighton, Cockcroft Building, Lewes Road, Brighton BN2 4GJ, UK

E-mail: j.g.mabley@brighton.ac.uk

Key words: keratinocytes, oxidative stress, poly(adenosine diphosphate-ribose) polymerase, $1 \alpha, 25$-dihydroxyvitamin D3, 7-dehydrocholesterol homodimers and catalyzes the cleavage of $\mathrm{NAD}^{+}$into nicotinamide and ADP-ribose. The latter is used to synthesize branched nucleic acid-like polymers with poly[adenosine diphosphate (ADP)-ribose] units covalently attached to nuclear acceptor proteins including histones, transcription factors and PARP itself (2). This poly(ADP-ribosyl)ation of these proteins contributes to inflammatory signal transduction processes. In addition, oxidative stress-induced overactivation of PARP consumes $\mathrm{NAD}^{+}$and consequently ATP, culminating in cell dysfunction or necrosis (2).

Activation of PARP has been implicated in the pathogenesis of stroke (3), myocardial ischemia (4), diabetes (5), diabetic complications $(6,7)$, shock $(8)$, traumatic central nervous system injury (9), arthritis (10), colitis (11), and various other forms of inflammation $(2,11)$. PARP is involved in the regulation of the activation of various pro-inflammatory transcription factors including NF-кB (12), AP-1 (13) ATF-2 and CREB (14). PARP regulates the cellular expression of many pro-inflammatory cytokines, chemokines and adhesion molecules (15).

Vitamin D is a lipid-soluble vitamin which is traditionally viewed as a regulator of mineral (calcium and phosphorous) homeostasis and maintenance of normal skeletal architecture (16). Additional studies have demonstrated that this vitamin is also involved in a host of cellular processes including cell differentiation, cell proliferation and immune function (16). Vitamin D, the biologically inactive moiety, is converted into the active form 1 1 ,25-dihydroxyvitamin D3 by hydroxylation reactions, which occur primarily in the liver and kidney (16), but have also been described in keratinocytes (17-20). Vitamin D has been shown to be anti-inflammatory (16) and able to protect against various inflammatory disease states including rheumatoid arthritis (21), type I diabetes (22), inflammatory bowel disease (23), transplant rejection (24) and multiple sclerosis (25). The anti-inflammatory action of vitamin D involves down-regulation of inflammatory chemokine and cytokine expression $(22,26)$, inhibition of transcription factor activation (27), and inhibition of $\mathrm{T}$ cell proliferation (28). As the anti-inflammatory effects of vitamin D overlap substantially with those of PARP inhibitors, we examined whether the active form of vitamin D inhibits PARP activation. 


\section{Materials and methods}

Reagents were obtained from the following sources: ${ }^{3} \mathrm{H}-\mathrm{NAD}$ was from Perkin-Elmer Inc. (Boston, MA, USA); vitamin D, 1 $\alpha, 25$-dihydroxyvitamin D3, $1 \alpha$-hydroxyvitamin D3, 25hydroxyvitamin D3, 7-dehydrocholesterol and ketoconazole were from Sigma (St. Louis, MO, USA); peroxynitrite was from Calbiochem (San Diego, CA, USA), and cell-free PARP assay was from Trevigen Inc. (Gaithersburg, MD, USA). Cell culture media and supplements were from Invitrogen (Carlsbad, CA, USA), and the RAW 264.7 cell line was from ATCC (Manassas, VA, USA).

Cell-free PARP assay. The activity of vitamin D3 and its metabolites against purified human PARP enzyme was determined using a commercially available kit (Trevigen). The assay was carried out in 96-well ELISA plates following the manufacturer's instructions. Briefly, wells were coated with $1 \mathrm{mg} / \mathrm{ml}$ histone $(50 \mu \mathrm{l} / \mathrm{well})$ at $4^{\circ} \mathrm{C}$ overnight. Plates were then washed four times with PBS and then blocked by adding $50 \mu 1$ of Strep-Diluent (supplied with the kit). After incubation ( $1 \mathrm{~h}$, room temperature) plates were washed four times with PBS. Appropriate dilutions of vitamin D3, its metabolites and a positive control (the PARP inhibitor PJ-34) were combined with a $2 \mathrm{X}$ PARP cocktail $\left(1.95 \mathrm{mM} \mathrm{NAD}^{+}\right.$, $50 \mu \mathrm{M}$ biotinylated $\mathrm{NAD}^{+}$in $50 \mathrm{mM}$ Tris $\mathrm{pH} 8.0,25 \mathrm{mM}$ $\mathrm{MgCl}_{2}$ ) and a high specific activity PARP enzyme (both supplied with the kit) in a volume of $50 \mu 1$. The reaction was allowed to proceed for $30 \mathrm{~min}$ at room temperature. After four washes in PBS, incorporated biotin was detected by peroxidase-conjugated streptavidine (1:500 dilution) and TACS Sapphire substrate.

PARP cell assay. The macrophage cell line RAW 264.7 was treated with a combination of peroxynitrite $(750 \mu \mathrm{M}) \pm$ various concentrations of vitamin D3 or its metabolites for $15 \mathrm{~min}$. For the measurement of PARP activity, the media was removed and replaced with $0.5 \mathrm{ml}$ HEPES ( $\mathrm{pH} 7.5$ ) containing $0.01 \%$ digitonin and ${ }^{3} \mathrm{H}-\mathrm{NAD}\left(0.5 \mu \mathrm{Ci} \mathrm{ml}^{-1}\right)$ for $20 \mathrm{~min}$. The cells were then scraped from the wells and placed in Eppendorf tubes containing $200 \mu 1$ of ice-cold $50 \%$ TCA (w/v), and the tubes were then placed at $4^{\circ} \mathrm{C}$. After $4 \mathrm{~h}$ the tubes were centrifuged at $1800 \mathrm{x}$ g for $10 \mathrm{~min}$, the supernatant was removed, and the pellet was washed twice with $500 \mu 1$ ice-cold 5\% TCA. The pellet was solubilized in $250 \mu 1 \mathrm{NaOH}(0.1 \mathrm{M})$ containing $2 \%$ SDS overnight at $37^{\circ} \mathrm{C}$, and the PARP activity was then determined by measuring the radioactivity incorporated using a Wallac scintillation counter. The solubilized protein $(250 \mu \mathrm{l})$ was mixed with $5 \mathrm{ml}$ of scintillant (ScintiSafe Plus, Fisher) before being counted for $10 \mathrm{~min}$. Results were expressed as percent of PARP activity seen without the addition of compounds.

In a second series of experiments $\mathrm{HaCaT}$ cells (kindly provided by Dr Ulrich Rodeck, Thomas Jefferson University, Philadelphia, PA, with the permission of Professor Norbert E. Fusenig, German Cancer Research Center, Heidelberg, Germany) were cultured in RPMI-1640 medium supplemented with $10 \%$ fetal bovine serum and $100 \mathrm{U} / \mathrm{ml}$ penicillin and $100 \mu \mathrm{g} / \mathrm{ml}$ streptomycin for $48 \mathrm{~h}$ before being incubated with vitamin $\mathrm{D}(10-300 \mu \mathrm{M})$ for $15 \mathrm{~min}, 4,8$, or $16 \mathrm{~h}$. The treated $\mathrm{HaCaT}$ cells were then exposed to peroxynitrite $(750 \mu \mathrm{M})$ for $15 \mathrm{~min}$, and the PARP activity was determined as above. Finally, HaCaT cells were treated with increasing doses of vitamin D, 7-dehydrocholesterol and 1 $\alpha, 25$-dihydroxyvitamin D3 \pm the cytochrome P450 enzyme inhibitor ketoconazole and irradiated with UVA and B. Cells were irradiated with $72 \mathrm{~mJ} / \mathrm{cm}^{2}$ of UVA and B using a Multiport Solar UV simulator (model 601, from Solar Light Co. Inc., Philadelphia, PA) with the dose being regulated by a PMA 2100 dose control system (Solar Light Co. Inc.). Cellular PARP activation was measured $2 \mathrm{~h}$ after irradiation as described above.

\section{Results}

Effect of vitamin $D$ on the activity of isolated human PARP enzyme. The active form of vitamin D, 1 $\alpha, 25$-dihydroxyvitamin D3, dose-dependently inhibited PARP with $40 \%$ inhibition being observed at $0.1 \mu \mathrm{M}$ increasing to $80 \%$ at $1 \mu \mathrm{M}$ (Table I). The inactive form of vitamin D exhibited a minor PARP-inhibitory activity with only $10 \%$ inhibition observed at $100 \mu \mathrm{M}$. The $1 \alpha$-hydroxyvitamin D3 form of vitamin D had no inhibitory activity at any of the concentrations tested (Table I). 25-Hydroxyvitamin D3 did show some PARP

Table I. Effect of vitamin D3 and its active metabolites on the activity of isolated high specific activity human poly(ADPribose) polymerase.

\begin{tabular}{|c|c|c|c|c|c|c|c|c|}
\hline \multirow[b]{2}{*}{ Drug } & \multicolumn{8}{|c|}{ Concentration } \\
\hline & $0.003 \mu \mathrm{M}$ & $0.01 \mu \mathrm{M}$ & $0.03 \mu \mathrm{M}$ & $0.1 \mu \mathrm{M}$ & $1 \mu \mathrm{M}$ & $10 \mu \mathrm{M}$ & $30 \mu \mathrm{M}$ & $100 \mu \mathrm{M}$ \\
\hline Vitamin D3 & - & - & - & - & $87 \pm 1^{\mathrm{a}}$ & $85 \pm 0.5^{\mathrm{a}}$ & $84 \pm 1^{\mathrm{a}}$ & $83 \pm 0.5^{\mathrm{a}}$ \\
\hline $1 \alpha$-hydroxyvitamin D3 & $104 \pm 3$ & $103 \pm 2$ & $99 \pm 0.4$ & $100 \pm 1$ & $100 \pm 1$ & $99 \pm 0.4$ & $103 \pm 1$ & $95 \pm 1$ \\
\hline 25-hydroxyvitamin D3 & $91 \pm 2$ & $83 \pm 1^{a}$ & $75 \pm 1^{\mathrm{a}}$ & $78 \pm 0.2^{\mathrm{a}}$ & $77 \pm 4^{a}$ & $79 \pm 1^{\mathrm{a}}$ & $82 \pm 2^{a}$ & $56 \pm 6^{a}$ \\
\hline 1 $\alpha, 25$-dihydroxyvitamin D3 & $81 \pm 0.3^{\mathrm{a}}$ & $78 \pm 1^{\mathrm{a}}$ & $74 \pm 1^{\mathrm{a}}$ & $64 \pm 2^{a}$ & $24 \pm 1^{\mathrm{a}}$ & $24 \pm 5^{\mathrm{a}}$ & - & - \\
\hline
\end{tabular}

Results were expressed as percent activity, where the activity of the untreated enzyme was considered 100\%. Purified human PARP was incubated for 45 min with $250 \mu$ M NAD \pm drug. Data were expressed as the mean \pm SEM $(n=3)$. Statistical analysis was carried out using one-way analysis of variance followed by the Student-Newman-Keuls multiple comparison post-hoc analysis where p $<0.05$ was considered significant; ${ }^{\mathrm{a}} \mathrm{p}<0.05$ vs. untreated cells. 
Table II. Effect of vitamin D3 and its active metabolites on poly(ADP-ribose) polymerase activity in RAW 264.7 cells treated with peroxynitrite.

\begin{tabular}{lcrrrrrc}
\hline & \multicolumn{7}{c}{ Concentration } \\
\cline { 2 - 7 } Drug & $0.03 \mu \mathrm{M}$ & $0.1 \mu \mathrm{M}$ & $0.3 \mu \mathrm{M}$ & $1 \mu \mathrm{M}$ & $3 \mu \mathrm{M}$ & $10 \mu \mathrm{M}$ & $100 \mu \mathrm{M}$ \\
\hline Vitamin D3 & - & - & $99 \pm 2$ & $97 \pm 7$ & $98 \pm 2$ & $104 \pm 4$ & $78 \pm 5^{\mathrm{a}}$ \\
1-hydroxyvitamin D3 & - & $100 \pm 3$ & $100 \pm 6$ & $118 \pm 8$ & $93 \pm 3$ & $85 \pm 2^{\mathrm{a}}$ & $65 \pm 1^{\mathrm{a}}$ \\
25-hydroxyvitamin D3 & - & $95 \pm 4$ & $96 \pm 4$ & $90 \pm 3$ & $74 \pm 1^{\mathrm{a}}$ & $70 \pm 2^{\mathrm{a}}$ & $65 \pm 3^{\mathrm{a}}$ \\
1,25-dihydroxyvitamin D3 & $90 \pm 5$ & $89 \pm 3^{\mathrm{a}}$ & $85 \pm 3^{\mathrm{a}}$ & $72 \pm 3^{\mathrm{a}}$ & $54 \pm 1^{\mathrm{a}}$ & - & - \\
\hline
\end{tabular}

Results were expressed as percent activity of the ONOO- $^{-}(750 \mu \mathrm{M})$-treated cells. The mouse macrophage RAW 264.7 cell line was treated with vitamin D3 and its active metabolites for 15 min prior to the addition of ONOO- for a further 15 min. The cellular PARP activity was then determined. All forms of vitamin D3 showed PARP inhibitory activity but the most active was the 1,25-dihydroxyvitamin D3. Data were expressed as the mean \pm SEM $(n=3)$. Statistical analysis was carried out using one-way analysis of variance followed by the StudentNewman-Keuls multiple comparison post-hoc analysis where $\mathrm{p}<0.05$ was considered significant; ${ }^{\mathrm{a}} \mathrm{p}<0.05$ vs. untreated cells.

inhibitory activity, reducing the activity by $40 \%$ at $100 \mu \mathrm{M}$ (Table I).

Effect of vitamin D on cellular PARP enzyme. Similar to the results obtained using isolated enzyme, $1 \alpha, 25$-dihydroxyvitamin D3 was the most effective at inhibiting peroxynitritestimulated PARP activity in the RAW 264.7 macrophage cell line with $50 \%$ inhibition being observed at $3 \mu \mathrm{M}$ (Table II). Vitamin D itself showed a $20 \%$ inhibition at $100 \mu \mathrm{M}$. The monohydroxylated forms of vitamin $\mathrm{D}$ also demonstrated PARP-inhibitory activity reduced by $45 \%$ at $100 \mu \mathrm{M}$ (Table II).

Effect of vitamin D on PARP activity in the human keratinocyte cell line $\mathrm{HaCaT}$. Incubation of $\mathrm{HaCaT}$ cells with various concentrations of vitamin D (for 15 min prior to the addition of peroxynitrite) concentration-dependently inhibited PARP activation (Fig. 1). As the time of incubation of the HaCaT cells with vitamin $\mathrm{D}$ increased prior to the addition of the peroxynitrite, the effectiveness of vitamin $\mathrm{D}$ in inhibiting PARP increased, especially at the lower doses of 10 and $30 \mu \mathrm{M}$ of vitamin $\mathrm{D}$ which had no inhibitory effect at $15 \mathrm{~min}$ but with a $>4$-h incubation time significantly reduced the HaCaT PARP activity in response to peroxynitrite (Fig. 1).

In a second series of experiments, $\mathrm{HaCaT}$ cells were exposed to $72 \mathrm{~mJ} / \mathrm{cm}^{2} \mathrm{UVA}$ and $\mathrm{B}$ radiation and PARP activity was measured $2 \mathrm{~h}$ later. Following irradiation PARP activity in the $\mathrm{HaCaT}$ cells doubled $(4008 \pm 252 \mathrm{cpm}$ to $9893 \pm 614, \mathrm{p}<0.001)$. Prior to irradiation, HaCaT cells were treated with increasing doses of vitamin D, 7-dehydrocholesterol (provitamin D) and 1 1 ,25-dihydroxyvitamin D3 and the PARP activity was again determined $2 \mathrm{~h}$ after irradiation. We found that all three forms of vitamin D concentration-dependently inhibited PARP activation (Fig. 2). To further characterize the mechanism by which vitamin D inhibits PARP, we simultaneously treated the HaCaT cells with the highest dose of vitamin D, 7-dehydrocholesterol or 1 $\alpha, 25$-dihydroxyvitamin D3 plus the cytochrome P450 enzyme inhibitor ketoconazole at either 5 or $10 \mu \mathrm{M}$. Ketoconazole partially reversed the inhibition of PARP seen with both vitamin $\mathrm{D}$ and 7-dehydrocholesterol at $300 \mu \mathrm{M}$, but had no effect on inhibition by $1 \alpha, 25$-dihydroxyvitamin D3 implicating

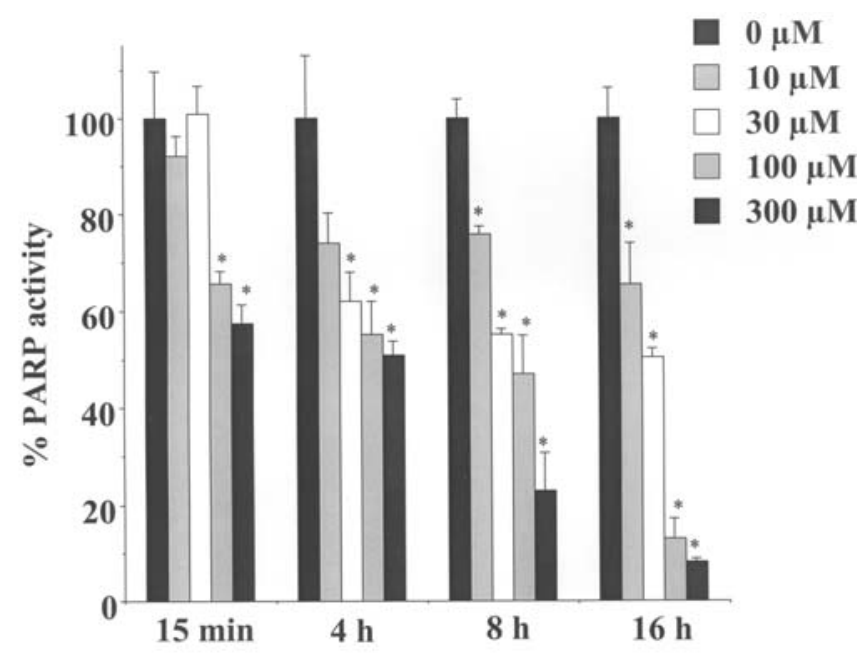

Figure 1. Treatment of human keratinocyte HaCaT cells with vitamin D3 protected against activation of PARP by peroxynitrite. HaCaT cells were incubated for $15 \mathrm{~min}, 4,8$, or $16 \mathrm{~h}$ with various concentrations of vitamin D3 prior to being treated with $\mathrm{ONOO}^{-}$at $750 \mu \mathrm{M}$ for $15 \mathrm{~min}$. PARP activity was then measured. The longer the incubation time with vitamin D3 the more effective the inhibitory action became suggesting that the inactive vitamin D3 was being converted into the active 1,25-dihydroxyvitamin D3. Data were expressed as the mean $\pm \operatorname{SEM}(n=3)$. ${ }^{*} \mathrm{p}<0.05$ was considered significant vs. untreated cells.

the cytochrome P450 enzyme system in converting vitamin D and 7-dehydrocholesterol to active PARP inhibitors (Fig. 2). Ketoconazole alone at $10 \mu \mathrm{M}$ had no effect on UV-induced PARP activity $(9893 \pm 614$ cpm vs. $9527 \pm 632$ in the treated cells, $\mathrm{p}=0.73$ ).

\section{Discussion}

We have demonstrated here for the first time that vitamin D exerts a concentration-dependent inhibitory effect on the nuclear enzyme poly(ADP-ribose) polymerase. Our studies determined that the dihydroxylated active form of vitamin $\mathrm{D}$, $(1 \alpha, 25$-dihydroxyvitamin D3) is a more potent PARP inhibitor than vitamin $\mathrm{D}$. The monohydroxylated forms, $1 \alpha-$ hydroxyvitamin D3 and 25-hydroxyvitamin D3 have little or 
A.

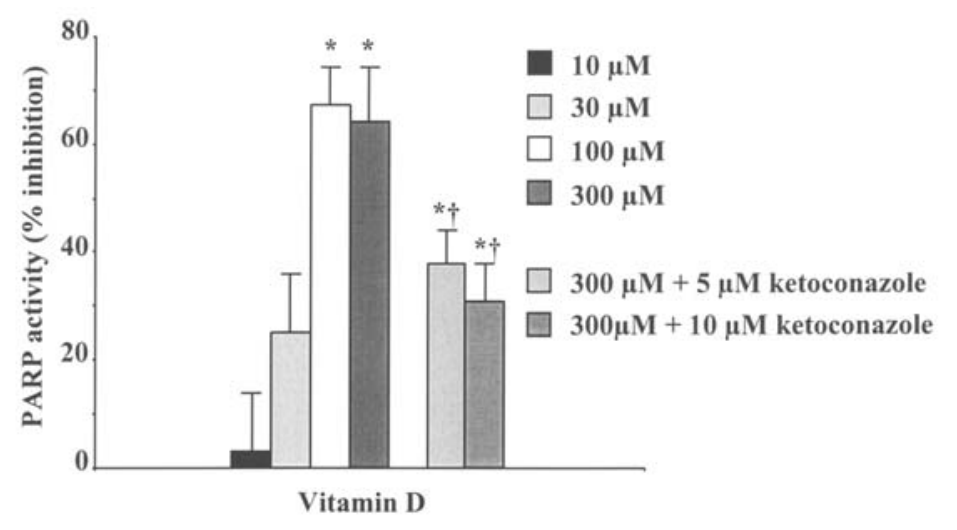

B.
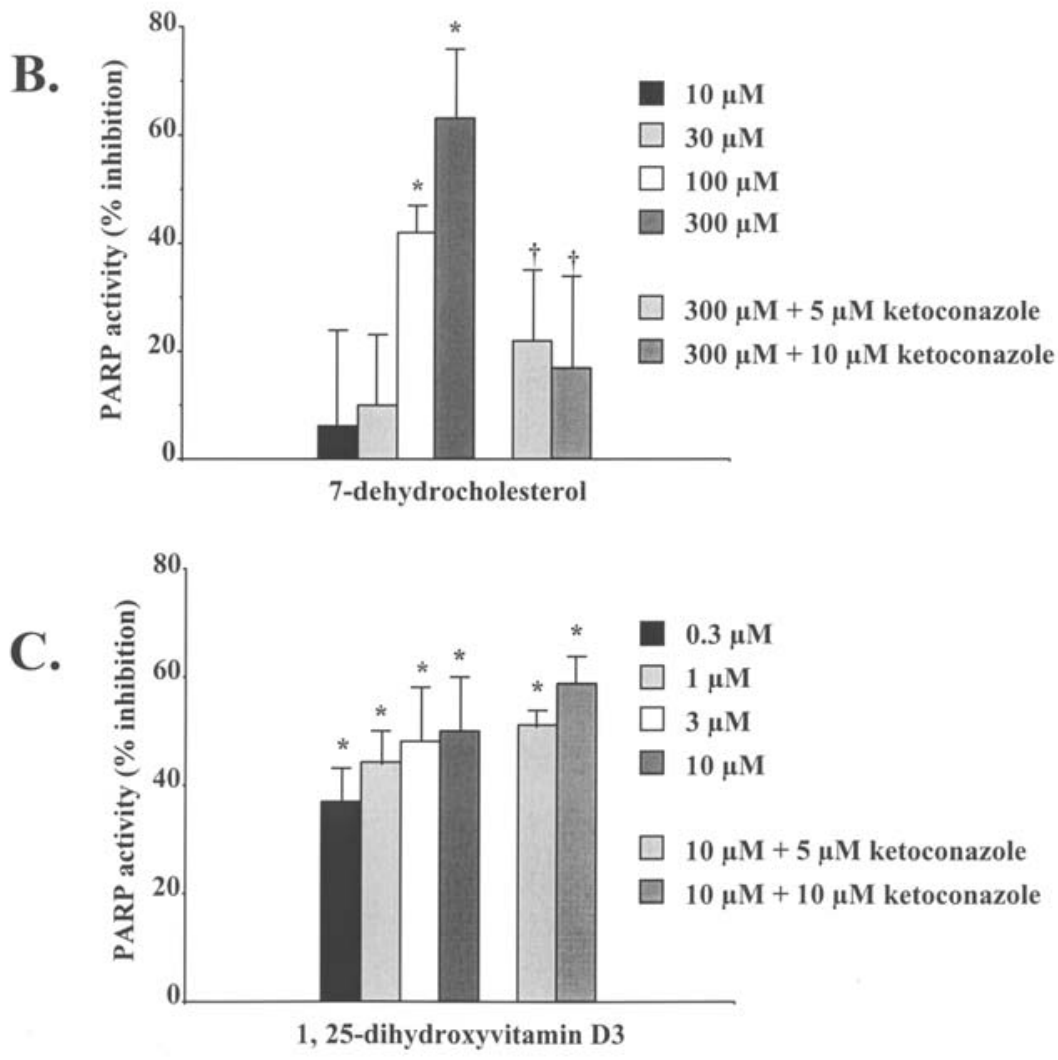

Figure 2. Effect of vitamin D (A), 3,7-dehydrocholesterol (provitamin D3) (B) and 1 $\alpha$,25-dihydroxyvitamin D3 (C), on poly(ADP-ribose) polymerase activity in $\mathrm{HaCaT}$ cells exposed to UV irradiation. Results were expressed as percent inhibition of the activity observed in untreated cells following UV exposure. The $\mathrm{HaCaT}$ cell lines were treated with the various concentrations of the vitamin D isoforms before being exposed to $72 \mathrm{~mJ} / \mathrm{cm}^{2} \mathrm{UVA}$ and $\mathrm{B}$, and $2 \mathrm{~h}$ after exposure the PARP activity was determined. All isoforms of vitamin D demonstrated concentration-dependent PARP inhibitory activity. The inhibitory effect of the precursors of 1 1 ,25-dihydroxyvitamin D3, vitamin D and 3,7-dehydrocholesterol, was blocked by the cytochrome P450 enzyme inhibitor ketoconazole, indicating that their conversion to $1 \alpha, 25$-dihydroxyvitamin D3 was required for PARP inhibition. Results were expressed as the mean \pm SEM ( $=3$ ). Statistical analysis was carried out using one-way analysis of variance followed by the Student-Newman-Keuls multiple comparison post-hoc analysis where p<0.05 was considered significant; ${ }^{*} \mathrm{p}<0.05$ vs. untreated cells, ${ }^{\dagger} \mathrm{p}<0.05$ vs. 300 (10) $\mu \mathrm{M}$ alone.

no PARP inhibitory effect. The results of our studies in the human keratinocyte cell line, $\mathrm{HaCaT}$, are consistent with the notion that UV irradiation-induced PARP activity can be inhibited by pro-vitamin D and vitamin D by a mechanism which involves their cellular conversion to $1 \alpha, 25$-dihydroxyvitamin D3.

Supraphysiological doses of vitamin D exert protective effects in inflammatory and non-inflammatory conditions, including type I diabetes, arthritis and cardiac failure (29). The anti-inflammatory effects of vitamin D include inhibition of pro-inflammatory chemokine and cytokine expression $(22,26)$ and inhibition of transcription factor activation $(27)$, effects duplicated by specific PARP inhibitors $(13,15)$. Survival of keratinocytes post UV-radiation was significantly greater following treatment with the active form of vitamin D, $1 \alpha, 25$-dihydroxyvitamin D3 (30). We propose, therefore, that the anti-inflammatory and cardioprotective effects of vitamin D may be, at least in part, mediated by the inhibition of PARP.

Our studies used well-characterized methods to determine PARP inhibitory activity, such as the isolated enzyme in a cell-free system $(31,32)$ and RAW 264.7 macrophages, which demonstrated considerable PARP activation following peroxynitrite treatment (32). In the cell-free assay we found that 1 $\alpha, 25$-dihydroxyvitamin D3 was the most potent PARP 
inhibitor and the only one which was active at concentrations which made it likely to be a PARP inhibitor in vivo. Vitamin D and its two monohydroxylated forms have some minor PARP inhibitory activity, but only at very high concentrations, which are probably unimportant for potential in vivo effects. In RAW 264.7 cells treated with peroxynitrite to induce PARP activation we found 1 $\alpha, 25$-dihydroxyvitamin D3 was the most potent PARP inhibitor, but both the monohydroxylated forms also had some inhibitory activity, possibly due to some cellular conversion of the monohydroxylated forms of vitamin D into $1 \alpha, 25$-dihydroxyvitamin D3.

Physiologically, vitamin D is converted to the biologically active metabolite 1 1 ,25-dihydroxyvitamin D3 by a cascade of reactions, which include hydroxylation at the C-25 position in the liver and at the $\mathrm{C}-1 \alpha$ position in the kidney. In 1998 Lehmann et al demonstrated for the first time that the human HaCaT cell line could metabolize both vitamin D and $1 \alpha$-hydroxyvitamin D3 into $1 \alpha, 25$-dihydroxyvitamin D3 $(33,34)$ and later demonstrated that this occurred not only in the $\mathrm{HaCaT}$ cell line but also in primary human skin cells (18). In our studies, vitamin D treatment of HaCaT cells inhibited peroxynitrite-induced PARP activation. As we increased the incubation time with vitamin D prior to peroxynitrite treatment, the vitamin became increasingly more effective at inhibiting PARP activation, especially at the lowest concentrations studied. This effect may be due to the conversion of vitamin D to its active metabolite over time.

Lehmann et al also investigated the UVB-induced conversion of 7-dehydrocholesterol, a precursor of vitamin D, to 1 $\alpha, 25$-dihydroxyvitamin D3 in HaCaT cells $(17,19)$. 7Dehydrocholesterol (provitamin D), when exposed to UVB radiation, was converted in vivo (35) and in vitro (36) to previtamin $\mathrm{D}$, which in turn was isomerized to vitamin $\mathrm{D}$. They also demonstrated that the cytochrome P450 enzyme inhibitor ketoconazole (37) blocked the UVB-mediated conversion of 7-dehydrocholesterol to $1 \alpha, 25$-dihydroxyvitamin D3 in human skin cells $(17,19)$. UV irradiation has been demonstrated to induce nitric oxide and peroxynitrite production in keratinocytes (38) an effect mediated by UVB-mediated activation of enzymes responsible for nitric oxide and superoxide production (38). This increase in nitrogen reactive species following UVB exposure is of particular importance in sunburn erythema. Peroxynitrite is a potent activator of PARP (39). When considering the direct effects of UV irradiation on DNA (40), it is likely that PARP will become activated in skin cells following UV light irradiation in vivo. Indeed, topical application of a PARP inhibitor has been shown to protect skin from acute photodamage (41). Here we found that in vitro $2 \mathrm{~h}$ after irradiation with UVA and B there was a doubling of PARP activity in the HaCaT cells.

The human skin is continually exposed to UV radiation and though it is not surprising that PARP becomes activated in extreme circumstances such as sunburn erythema it is conceivable that even under normal exposure PARP may become activated in skin cells. Therefore, it is likely that skin cells have built-in protection mechanisms to prevent overactivation of PARP, and vitamin D may serve as one such protective mechanism. We found that exposing $\mathrm{HaCaT}$ cells to UV irradiation in the presence of 7-dehydrocholesterol, vitamin D or 1 $\alpha, 25$-dihydroxyvitamin D3 significantly reduced cellular UV-induced PARP activation. In addition we found that the presence of the cytochrome P450 enzyme inhibitor, ketoconazole, significantly blunted the PARP inhibitory effect of both 7-dehydrocholesterol and vitamin D but not $1 \alpha, 25$-dihydroxyvitamin D3 suggesting that by blocking the conversion of vitamin D to $1 \alpha, 25$-dihydroxyvitamin D3 the PARP inhibitory effect was also blocked, hence further strengthening the notion that the $1 \alpha, 25$ dihydroxyvitamin D3 form of vitamin D is the active PARP inhibitor.

In conclusion, we described that vitamin $\mathrm{D}$ has a novel pharmacological effect as a PARP inhibitor and we provided multiple lines of evidence to suggest that its active metabolite, $1 \alpha, 25$-dihydroxyvitamin D3, is responsible for this activity. Therefore, we speculate that at least in part vitamin D's cellular actions may be mediated by the inhibition of PARP. We also demonstrated that keratinocytes exposed to UV irradiation have increased PARP activation and that this is attenuated by $1 \alpha, 25$-dihydroxyvitamin D3 treatment, as well as by the active metabolite precursors, 7-dehydrocholesterol and vitamin D. Therefore, we propose that the UV-radiationmediated vitamin D generation system in keratinocytes not only provides vitamin $\mathrm{D}$ for the whole body but also acts as an intrinsic self-preservation mechanism for keratinocytes to prevent pathological over-activation of PARP in response to sunlight exposure or other external sources of UV radiation.

\section{References}

1. Lautier D, Lagueux J, Thibodeau J, Menard L and Poirier GG: Molecular and biochemical features of poly(ADP-ribose) metabolism. Mol Cell Biochem 122: 171-193, 1993.

2. Virag L and Szabó C: The therapeutic potential of poly(ADPribose) polymerase inhibitors. Pharmacol Rev 54: 375-429, 2002.

3. Abdelkarim GE, Gertz K, Harms C, et al: Protective effects of PJ34, a novel, potent inhibitor of poly(ADP-ribose) polymerase (PARP) in in vitro and in vivo models of stroke. Int J Mol Med 7: 255-260, 2001.

4. Pacher P, Liaudet L, Mabley J, Komjati K and Szabó C: Pharmacologic inhibition of poly(adenosine diphosphate-ribose) polymerase may represent a novel therapeutic approach in chronic heart failure. J Am Coll Cardiol 40: 1006-1016, 2002.

5. Mabley JG, Suarez-Pinzon WL, Hasko G, et al: Inhibition of poly (ADP-ribose) synthetase by gene disruption or inhibition with 5-iodo-6-amino-1,2-benzopyrone protects mice from multiple-low-dose-streptozotocin-induced diabetes. Br J Pharmacol 133: 909-919, 2001.

6. Garcia Soriano F, Virag L, Jagtap P, et al: Diabetic endothelial dysfunction: the role of poly(ADP-ribose) polymerase activation. Nat Med 7: 108-113, 2001.

7. Pacher P, Liaudet L, Soriano FG, Mabley JG, Szabó E and Szabó C: The role of poly(ADP-ribose) polymerase activation in the development of myocardial and endothelial dysfunction in diabetes. Diabetes 51: 514-521, 2002.

8. Jagtap P, Soriano FG, Virag L, et al: Novel phenanthridinone inhibitors of poly (adenosine 5'-diphosphate-ribose) synthetase: potent cytoprotective and antishock agents. Crit Care Med 30: 1071-1082, 2002.

9. Whalen MJ, Clark RS, Dixon CE, et al: Traumatic brain injury in mice deficient in poly-ADP(ribose) polymerase: a preliminary report. Acta Neurochir (Suppl) 76: 61-64, 2000.

10. Szabo A, Hake P, Salzman AL and Szabó C: 3-aminobenzamide, an inhibitor of poly (ADP-ribose) synthetase, improves hemodynamics and prolongs survival in a porcine model of hemorrhagic shock. Shock 10: 347-353, 1998.

11. Mabley JG, Jagtap P, Perretti M, et al: Anti-inflammatory effects of a novel, potent inhibitor of poly (ADP-ribose) polymerase. Inflamm Res 50: 561-569, 2001. 
12. Oliver FJ, Menissier-de Murcia J, Nacci C, et al: Resistance to endotoxic shock as a consequence of defective NF-kappaB activation in poly (ADP-ribose) polymerase-1 deficient mice. EMBO J 18: 4446-4454, 1999.

13. Andreone TL, O'Connor M, Denenberg A, Hake PW and Zingarelli B: Poly(ADP-ribose) polymerase-1 regulates activation of activator protein-1 in murine fibroblasts. J Immunol 170: 2113-2120, 2003.

14. Ha HC: Defective transcription factor activation for proinflammatory gene expression in poly(ADP-ribose) polymerase 1-deficient glia. Proc Natl Acad Sci USA 101: 5087-5092, 2004.

15. Hasko G, Mabley JG, Nemeth ZH, Pacher P, Deitch EA and Szabó C: Poly(ADP-ribose) polymerase is a regulator of chemokine production: relevance for the pathogenesis of shock and inflammation. Mol Med 8: 283-289, 2002.

16. Nagpal S, Lu J and Boehm MF: Vitamin D analogs: mechanism of action and therapeutic applications. Curr Med Chem 8: 1661-1679, 2001.

17. Lehmann B, Knuschke P and Meurer M: UVB-induced conversion of 7-dehydrocholesterol to 1 alpha,25-dihydroxyvitamin D3 (calcitriol) in the human keratinocyte line HaCaT. Photochem Photobiol 72: 803-809, 2000.

18. Lehmann B, Rudolph T, Pietzsch J and Meurer M: Conversion of vitamin D3 to 1alpha,25-dihydroxyvitamin D3 in human skin equivalents. Exp Dermatol 9: 97-103, 2000.

19. Lehmann B, Genehr T, Knuschke P, Pietzsch J and Meurer M: UVB-induced conversion of 7-dehydrocholesterol to 1alpha,25dihydroxyvitamin D3 in an in vitro human skin equivalent model. J Invest Dermatol 117: 1179-1185, 2001.

20. Lehmann B, Sauter W, Knuschke P, Dressler S and Meurer M: Demonstration of UVB-induced synthesis of 1 alpha,25dihydroxyvitamin D3 (calcitriol) in human skin by microdialysis. Arch Dermatol Res 295: 24-28, 2003.

21. Cantorna MT, Hayes CE and DeLuca HF: 1,25-Dihydroxycholecalciferol inhibits the progression of arthritis in murine models of human arthritis. J Nutr 128: 68-72, 1998.

22. Gysemans CA, Cardozo AK, Callewaert H, et al: 1,25Dihydroxyvitamin D3 modulates expression of chemokines and cytokines in pancreatic islets: implications for prevention of diabetes in nonobese diabetic mice. Endocrinology 146: 1956-1964, 2005.

23. Cantorna MT, Munsick C, Bemiss C and Mahon BD: 1,25Dihydroxycholecalciferol prevents and ameliorates symptoms of experimental murine inflammatory bowel disease. J Nutr 130: 2648-2652, 2000 .

24. Adorini L: 1,25-Dihydroxyvitamin D3 analogs as potential therapies in transplantation. Curr Opin Investig Drugs 3: 1458-1463, 2002.

25. Meehan TF and DeLuca HF: The vitamin D receptor is necessary for 1alpha,25-dihydroxyvitamin $\mathrm{D}(3)$ to suppress experimental autoimmune encephalomyelitis in mice. Arch Biochem Biophys 408: 200-204, 2002.

26. Lyakh LA, Sanford M, Chekol S, Young HA and Roberts AB: TGF-[beta] and vitamin D3 utilize distinct pathways to suppress IL-12 production and modulate rapid differentiation of human monocytes into CD83+ dendritic cells. J Immunol 174: 2061-2070, 2005.
27. D'Ambrosio D, Cippitelli M, Cocciolo MG, et al: Inhibition of IL-12 production by 1,25-dihydroxyvitamin D3. Involvement of NF-kappaB downregulation in transcriptional repression of the p40 gene. J Clin Invest 101: 252-262, 1998.

28. Muller K and Bendtzen K: 1,25-Dihydroxyvitamin D3 as a natural regulator of human immune functions. J Investig Dermatol Symp Proc 1: 68-71, 1996.

29. Achinger SG and Ayus JC: The role of vitamin D in left ventricular hypertrophy and cardiac function. Kidney Int (Suppl) 95: S37-S42, 2005.

30. Gupta R, Dixon KM, Deo SS, et al: Photoprotection by 1,25 dihydroxyvitamin $\mathrm{D}(3)$ is associated with an increase in $\mathrm{p} 53$ and a decrease in nitric oxide products. J Invest Dermatol 127: 707$715,2007$.

31. Bakondi E, Bai P, Szabo EE, et al: Detection of poly(ADPribose) polymerase activation in oxidatively stressed cells and tissues using biotinylated NAD substrate. J Histochem Cytochem 50: 91-98, 2002.

32. Jagtap PG, Southan GJ, Baloglu E, et al: The discovery and synthesis of novel adenosine substituted 2,3-dihydro- $1 \mathrm{H}$ isoindol-1-ones: potent inhibitors of poly(ADP-ribose) polymerase-1 (PARP-1). Bioorg Med Chem Lett 14: 81-85, 2004.

33. Lehmann B, Pietzsch J, Kampf A and Meurer M: Human keratinocyte line $\mathrm{HaCaT}$ metabolizes 1alpha-hydroxyvitamin D3 and vitamin D3 to 1alpha,25-dihydroxyvitamin D3 (calcitriol). J Dermatol Sci 18: 118-127, 1998.

34. Lehmann B and Meurer M: Extrarenal sites of calcitriol synthesis: the particular role of the skin. Recent Results Cancer Res 164: 135-145, 2003.

35. Holick MF, MacLaughlin JA, Clark MB, et al: Photosynthesis of previtamin D3 in human skin and the physiologic consequences. Science 210: 203-205, 1980.

36. Nemanic MK, Whitney J and Elias PM: In vitro synthesis of vitamin D-3 by cultured human keratinocytes and fibroblasts: action spectrum and effect of AY-9944. Biochim Biophys Acta 841: 267-277, 1985

37. Wilkinson CF, Hetnarski K, Cantwell GP and Di Carlo FJ: Structure-activity relationships in the effects of 1-alkylimidazoles on microsomal oxidation in vitro and in vivo. Biochem Pharmacol 23: 2377-2386, 1974.

38. Deliconstantinos G, Villiotou V and Stavrides JC: Increase of particulate nitric oxide synthase activity and peroxynitrite synthesis in UVB-irradiated keratinocyte membranes. Biochem J 320: 997-1003, 1996.

39. Virag L, Szabo E, Bakondi E, et al: Nitric oxide-peroxynitritepoly(ADP-ribose) polymerase pathway in the skin. Exp Dermatol 11: 189-202, 2002.

40. Matsumura Y and Ananthaswamy HN: Toxic effects of ultraviolet radiation on the skin. Toxicol Appl Pharmacol 195: 298-308, 2004.

41. Farkas B, Magyarlaki M, Csete B, et al: Reduction of acute photodamage in skin by topical application of a novel PARP inhibitor. Biochem Pharmacol 63: 921-932, 2002. 